\title{
FGM/C and ECM: Drawing lessons from research
}

Jacinta Muteshi-Strachan

Population Council

Follow this and additional works at: https://knowledgecommons.popcouncil.org/departments_sbsr-rh

Part of the Demography, Population, and Ecology Commons, Family, Life Course, and Society Commons, Gender and Sexuality Commons, International Public Health Commons, Maternal and Child Health Commons, Medicine and Health Commons, and the Women's Health Commons How does access to this work benefit you? Let us know!

\section{Recommended Citation}

Muteshi-Strachan, Jacinta. 2019. "FGM/C and ECM: Drawing lessons from research," presentation at the Child Marriage Research Meeting, Geneva, Switzerland. 


\title{
Evidence to End FGM/C (2)
}

\section{FGM/C and ECM: \\ Drawing Lessons from Research}

\author{
Jacinta Muteshi-Strachan, PhD. \\ Population Council
}

Conference: "Child Marriage Research Meeting: Session on drawing lessons from research on related issues \& on forging convergence".

Geneva, Switzerland.

September $30^{\text {th }}$ to $4^{\text {th }}$ October 2019. 


\section{Introduction}

Global consensus: FGM/C and ECM as gendered, socially endorsed harmful practices*.

- Female genital Mutilation/Cutting (FGM/C) often linked to marriageability and thought to be associated with Early/Child Marriage (ECM)

- ECM and $\mathrm{FGM} / \mathrm{C}$ may operate alone, in combination or collectively

$\checkmark$ But little rigorous research to clarify the relationship between FGMC \& ECM to inform policy, programming and investment. 
What are we learning from the FGM/C

Research programme? "Investments need to be evidence based"

Understand the geography and pattern of practice key for targeting investment

- Critical to highlight sub-national level data, identify hot spots/areas of risk.

Provide rigorous evidence:

- "Cultural" practices evolve; shifting discourses and norms, \& underpinning structures.

- Intervention elements that make a difference

- Measurement challenges: understanding the how \& efficacy of complex interventions.

Legislation: a challenged and mixed record 


\section{What does the Evidence say about links between ECM and FGM/C?}

Recent Demographic and Health survey (DHS) and Multiple Cluster Survey (MICS) data for 10 Sub-Saharan countries and review of the literature

* Prevalence: Significant variations in national, sun-national \& ethnic groups -by country.

* Associations: Between ECM and FGM/C vary by country, along with predictors for each.

- Dynamics in which practices occur vary

- Contextual realities: some settings one practice in decline, in another sustained or rising.

- In most of our study countries could be a prerequisite.
* Similarities in causes and underlying drivers:

- Affords social capital

- Maintenance of chastity

- Gendered relational practices based on power structures. 


\section{What are the Implications?}

More evidence needed on the best strategies for supporting abandonment of ECM and FGM/C including :
1.Knowledge of the drivers and consequences of FGMC \&ECM in specific contexts, to build a detailed understanding that also enables generalizations

2.Impact of FGM/C and ECM interventions on wider gender norms, which requires strengthened monitoring and evaluation frameworks and systems

3. Need for more attention to theory-based intervention and evaluation designs

4.Improved coordination among advocates, implementers, policy makers and researchers 
What are the opportunities for

convergence between FGMC and ECM?

FGM/C a precursor in some context for ECM but not in other contexts.

- In contexts where both practices prevalent may not always be strongly associated.....

HOWEVER:

- Both perceived as having important roles that range from "securing the well being and physical security of daughters; and/or securing family honour; and/or offering social and economic advantage to families; and/or enabling transition to adulthood.... But in ways that sustain some of the structural injustices that girls and women may experience. 


\section{What are the opportunities for convergence between FGMC and ECM?}

\section{Variations and complexities of local realities means approaches can't be standard:}

BUT:

- Secondary education an enabling condition: Educated mothers likely to keep children in school \& not support FGM/C or ECM. Enabled delayed marriage;

$\checkmark$ Tested Intervention packages* :educational interventions (provision of school materials, conditional cash transfers, community conversations on social norms) have high quality results but are they sustainable? Do they translate into livelihood security?

- Laws provide support for abandonment of FGMC \& ECM: - Infrastructural responses required? 


\section{Conclusion}

\section{Lesson:}

Our improved understanding of the emerging structural factors that underpin and/or sustain FGM/C are beginning to clarify the mechanisms of action required, \& call for more multi-sectoral intervention designs. 


\section{Evidence to End FGM/C}

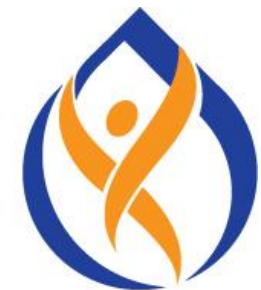

Research to Help Girls and Women Thrive

The Evidence to End FGM/C programme consortium generates evidence to inform and influence investments, policies, and programs for ending female genital mutilation/cutting in different contexts.

Evidence to End FGM/C is led by the Population Council in partnership with the Africa Coordination Centre for Abandonment of Female Genital Mutilation/Cutting (Kenya); Gender and Reproductive Health \& Rights Centre (Sudan); MannionDaniels, Ltd.; Population Reference Bureau; University of California, San Diego; and University of Washington. Evidence to End FGM/C is funded by UK aid by the UK Government.

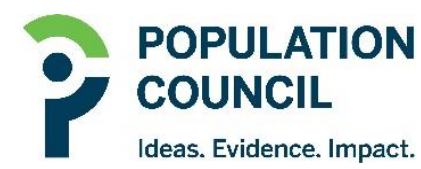

Ideas. Evidence. Impact.
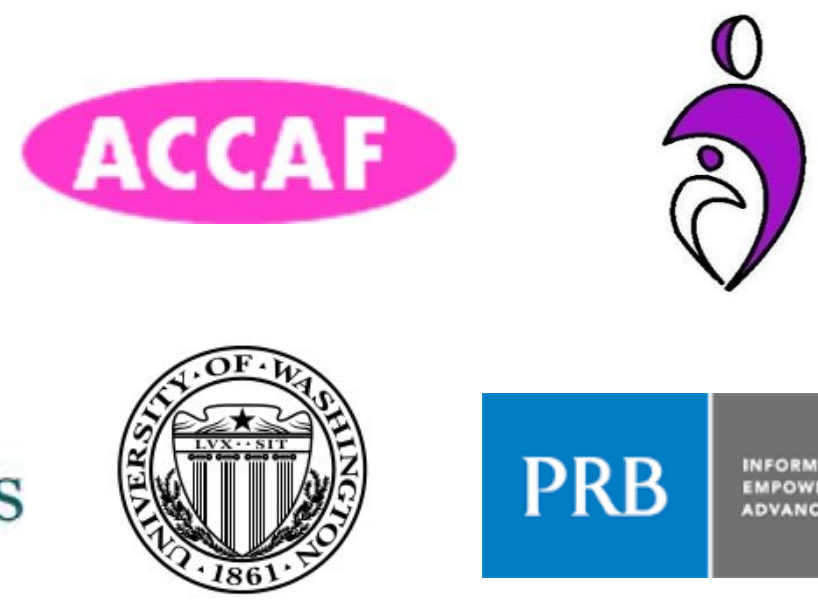
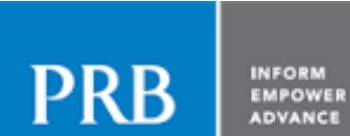
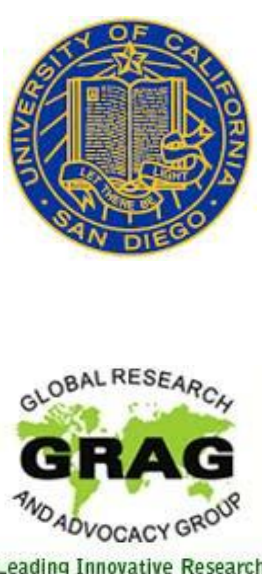

Leading Innovative Research 